\title{
Development of an affinity cryogel for one step purification of lysozyme from chicken egg white
}

\author{
Paula Chequer Gouveia Mól ${ }^{\mathrm{a}}$, Lizzy Ayra Alcântara Veríssimo ${ }^{\mathrm{b}}$, Monique Renon Eller $^{\mathrm{c}}$, \\ Valéria Paula Rodrigues Minim ${ }^{\mathrm{c}}$, Luis Antonio Minim ${ }^{\mathrm{c}, *}$ \\ a Department of Food Engineering and Technology, UNESP- São Paulo State University, 15054-000, São José do Rio Preto, SP, Brazil \\ b Department of Food Science, Federal University of Lavras, 37200-000, Lavras, MG, Brazil

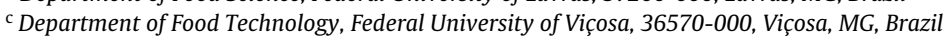

\section{A R T I C L E I N F O}

\section{Article history:}

Received 11 October 2016

Received in revised form

22 November 2016

Accepted 18 December 2016

Available online 31 December 2016

\section{Keywords:}

Lysozyme

Cryogel

Affinity chromatography

Purification

\begin{abstract}
A B S T R A C T
In this study, a supermacroporous polyacrylamide cryogel was produced by cryo-polymerization and activated with Tris(hydroxymethyl)aminomethane (Tris-cryogel) to be applied as an affinity ligand for a one step purification of lysozyme (LYZ), directly from chicken egg white (EW). The Tris-cryogel presented interconnected pores with size varying in the range of $20-80 \mu \mathrm{m}$ and swelling capacity of $19.6 \pm 0.9 \mathrm{~g} / \mathrm{g}$. The axial dispersion of the Tris-cryogel was analyzed at different flow velocities and mobile phase viscosities. It was verified that higher viscosity resulted in a higher degree of dispersion, causing the HETP values to increase from $0.04 \mathrm{~cm}$ to $0.8 \mathrm{~cm}$. Adsorption isotherms were measured at $15^{\circ} \mathrm{C}$ and $35^{\circ} \mathrm{C}$ at $\mathrm{pH} 7.5$. A Langmuir model was fitted to the equilibrium data, with a maximum adsorptive capacity of $285 \mathrm{mg} / \mathrm{g}$ at $15^{\circ} \mathrm{C}$ and $363 \mathrm{mg} / \mathrm{g}$ at $35^{\circ} \mathrm{C}$. Thermodynamic analysis based on the Van't Hoff relationship showed that the process was spontaneous and enthalpically driven. Lysozyme was purified directly from egg white in a one step purification process at different $\mathrm{pH}$ values $(7.5,8.5$ and 9.5). Independent of the $\mathrm{pH}$, the specificity of Tris-cryogel for lysozyme adsorption was confirmed. At pH 7.5, yield and purification fold were higher (30\% and 45). In addition, the effect of the dilution rate on egg white and flow velocity were also analyzed and it was shown that flow velocity did not affected purification and column efficiency, and that diluting the egg white increased yield to $70 \%$ with a purification fold of 23 . Results show Tris-cryogel is a promising matrix for use in high throughput purification of lysozyme from egg white.
\end{abstract}

(c) 2016 Elsevier B.V. All rights reserved.

\section{Introduction}

Lysozyme (LYZ) is an antimicrobial enzyme widely distributed in nature that presents catalytic activity in the hydrolysis of some components of the bacterial cell wall. Because of its antimicrobial properties, this enzyme has been commonly used in pharmaceutical and food industries [1,2].

Commercial lysozyme is extracted from chicken egg white and represents about $3.4 \%$ of egg white proteins [1]. It is a small protein, composed of a single polypeptide chain of 129 amino acids. It contains four cysteine pairs that form disulfide bridges. Its molar mass is $14.3 \mathrm{kDa}$ and the isoelectric point is close to $11[1,3-5]$.

The potential for technological lysozyme applications has stimulated interest in the development of new materials and methodologies for its isolation. Several techniques have been

\footnotetext{
* Corresponding author.

E-mail address: lminim@ufv.br (L.A. Minim).
}

reported for lysozyme purification, including chromatographic process such as ion exchange chromatography [6], hydrophobic interaction [7] and affinity chromatography [8-11].

Affinity liquid chromatography is an effective method for biomolecule purification, because of the specific retention of the target compound, generating high purity products. Certain specific binding materials are very expensive however, making this technique impractical. Thus, it is necessary to develop new affinity supports that are simple, effective and inexpensive. Quan et al. [12] and Kang et al. [13] studied the interaction between lysozyme and the compound tris hydroxymethyl aminomethane. They demonstrated the existence of a weak, but specific interaction, with lysozyme being selectively captured by Tris immobilized support and then eluted under mild conditions, allowing its recovery. The interaction is due to hydrogen bounds formed between the amino acids Aps52, Glu35 and Ala107 of lysozyme and the hydroxyl triad $(\mathrm{OH})$ present in Tris structure [12].

Chicken egg white is a type of raw material used in bioseparation, which is somewhat viscous and must be diluted before 
application [14]. Viscosity is an important property that could cause problems in pumping operations and thus increase the pressure drop through the column. Traditional chromatographic supports, while very efficient, create some resistance to mobile phase flow [4] and may lead to some operational problems such as clogging.

Polymeric gels produced in freezing conditions, known as cryogels, have become a very useful technique in the field of bioseparation [15]. They were introduced as a new generation of chromatographic matrices because of their highly porous structure and low flow resistance. These properties play an important role in the performance and speed of the separation processes and allow direct processing of crude extracts without prior clarification and dilution. Cryogels are also characterized by high accessibility to binding sites and negligible internal mass transfer limitations. Therefore, it contributes to optimize time process and consumption of water and other materials. In addition, chromatographic processes could be developed under high flow rates and therefore in short periods [16].

This work reports chicken egg white lysozyme purification by affinity chromatography with poly (acrylamide) cryogel with Tris hydroxymethyl aminomethane as an affinity ligand (Triscryogel). The Tris-cryogel was characterized by scanning electron microscopy (SEM), swelling tests, hydraulic permeability and porosity. Axial dispersion was studied in terms of mobile phase viscosity and flow velocity with the use of nonreactive tracer pulse experiments. Lysozyme adsorption isotherms and the column purification performance were also studied.

\section{Materials and methods}

\subsection{Materials}

Acrylamide (AAm, 99\%), N,N'-methylene-bis-acrylamide (MAAm, 99\%), ammonium persulfate (APS), $N, N N^{\prime}, N$ '-tetramethylethylene-diamine (TEMED), allyl glycidyl eter (AGE, 99\%), tris hydroxymethyl aminomethane and sodium borohydrate were purchased from Sigma-Aldrich (St. Louis, USA). Others chemical reagents (all of analytical grade) and protein standards were also obtained from Sigma Aldrich. Ultrapure water was used in all experiments (Milli-Q System, Millipore Inc., USA). Fresh chicken eggs were obtained from a local store.

\subsection{Methods}

\subsubsection{Cryogel preparation}

The cryogel was prepared by dissolving monomers of AAm $(4.7 \% \mathrm{~m} / \mathrm{v}), \operatorname{MAAm}(1.3 \% \mathrm{~m} / \mathrm{v})$ and $1 \mathrm{~mL}$ of AGE in deionized water to a final volume of $25 \mathrm{~mL}$. The mixture was degassed for $5 \mathrm{~min}$ in an ultrasound bath. The polymerization reaction started with $23.8 \mu \mathrm{L}$ of TEMED and $100 \mu \mathrm{L}$ of APS $(27.5 \% \mathrm{~m} / \mathrm{v})$ in an ice bath. The mixture was immediately poured into $3 \mathrm{~mL}$ plastic syringes and into an HR 10/15 glass column (GE Healthcare, Uppsala, Sweden). The column and syringes were sealed and immersed in an ethanol bath (Model 0214M2, Quimis, Brazil) at $-12{ }^{\circ} \mathrm{C}$ for $24 \mathrm{~h}$. Afterward, the column was thawed at room temperature and washed with $200 \mathrm{~mL}$ of deionized water.

Tris was immobilized by covalent bonds between epoxy groups on the cryogel surface and amino groups present in the Tris molecule. The cryogel was initially immersed in $50 \mathrm{~mL}$ of sodium phosphate buffer $(2.5 \mathrm{mmol} / \mathrm{L}$; $\mathrm{pH} 9.0)$ containing $18.8 \mathrm{~g}$ of Tris, at $60^{\circ} \mathrm{C}$ for $48 \mathrm{~h}$. The cryogel was then immersed in $50 \mathrm{~mL}$ of sodium carbonate buffer $(0.2 \mathrm{~mol} / \mathrm{L}$; pH 9.2) containing $5.78 \mathrm{~g}$ of sodium borohydrate at $0{ }^{\circ} \mathrm{C}$ for $1 \mathrm{~h}$. Afterward, the activated Tris-cryogel was immersed in ultrapure water for $24 \mathrm{~h}$ to remove residuals of activation agents.

\subsubsection{Characteristics of tris-cryogel matrices}

2.2.2.1. Swelling capacity. The swelling capacity of the Tris-cryogel was determined according to Savina et al. [17], by immersing dried cryogels of a certain weight $\left(m_{d}\right)$ in $50 \mathrm{~mL}$ of water for $24 \mathrm{~h}$. Excess water was removed from the matrices and the wet weight was measured $\left(m_{w}\right)$. The swelling capacity was determined using Eq. (1).

$S=\frac{m_{w}-m_{d}}{m_{d}}$

2.2.2.2. Scanning electron microscopy. Scanning electron microscopy (SEM) was done to evaluate the macroporous structures and pore size of the Tris-cryogel. A small sample cut from the center of the dried cryogel was coated with gold/palladium (40/60). The gel structure was examined using a scanning electron microscope (LEO 1430 VP, Zeiss, Jena, Germany) operated at $15 \mathrm{kV}$.

2.2.2.3. Porosity and axial dispersion. Residence time distribution (RTD) was measured on a preparative chromatographic system Äkta Pure 25 M (GE Healthcare Bio-Sciences AB, Uppsala, Sweden) using an HR 10/15 glass column (GE Healthcare, Uppsala, Sweden) at various fluid velocities $(0.6-10.2 \mathrm{~cm} / \mathrm{min})$ at $25^{\circ} \mathrm{C}$, using acetone pulse $(100 \mu \mathrm{L}, 1 \% \mathrm{v} / \mathrm{v})$ as a tracer. The mobile phase was composed of a water solution of poly (ethylene glycol) $(0,2.5,5.0$ and $7.5 \% \mathrm{w} / \mathrm{w}$ ) with corresponding viscosity of $1.0 \mathrm{mPa} \mathrm{s}, 1.48 \mathrm{mPa}$, $2.065 \mathrm{mPa}$ s and $3.048 \mathrm{mPa}$ s. A UV detector monitored the corresponding peak $(280 \mathrm{~nm})$ at the column exit. All analyses were done in duplicate.

The mean residence time $\left(t_{R}\right)$ and variance $\left(\sigma_{t}^{2}\right)$ were obtained from the RTD curves by the momentum method. $E_{\theta}$ functions were determined according to Eq. (2):

$E_{\theta}=t_{R} \cdot \frac{A b s(t)}{\int_{0}^{\infty} A b s(t) d t}$

Porosity $\left(\varepsilon_{T}\right)$ was determined by linear regression of Eq. (3) [18]:

$t_{R}=\varepsilon_{T} \cdot \frac{L}{U}$

where $L(\mathrm{~cm})$ is the column length and $U(\mathrm{~cm} / \mathrm{min})$ is the superficial fluid velocity.

The axial dispersion coefficients at different flow velocities were determined by non-linear regression of Eq. (4) [19] using the variance and the mean residence time of the corresponding RTD curve under closed-vessel boundary conditions.

$\frac{\sigma_{\boldsymbol{t}}^{2}}{\boldsymbol{t}_{\boldsymbol{R}}^{2}}=2\left(\frac{\boldsymbol{D}_{\boldsymbol{a x}}}{\boldsymbol{u L}}\right)-2\left(\frac{\boldsymbol{D}_{\boldsymbol{a x}}}{\boldsymbol{u L}}\right)^{2}\left[1-\exp \left(-\frac{\boldsymbol{u L}}{\boldsymbol{D}_{\boldsymbol{a x}}}\right)\right]$

where $D_{a x}$ is the axial dispersion coefficient and $u$ is the interstitial fluid velocity through the column $\left(u=U / \varepsilon_{T}\right)$. Height equivalent to theoretical plate (HETP) was calculated according to Eq. (5) [20]:

$H E T P=L \frac{\sigma_{t}^{2}}{t_{R}^{2}}$

2.2.2.4. Hydraulic permeability. The pressure drop of the column was estimated using degassed deionized water as mobile phase at different flow rates $(0.6-12.7 \mathrm{~cm} / \mathrm{min})$. Hydraulic permeability was determined by linear regression of the Darcy-Weisbach equation in the laminar region (Eq. (6)).

$\frac{\Delta P_{w}}{L}=-\frac{\mu_{w}}{K_{w}} \cdot U$

where $\Delta P_{w}$ is the pressure drop through the column, $\mu_{w}$ is water viscosity and $K_{w}$ is hydraulic permeability. 


\subsubsection{Adsorption isotherms and thermodynamic analysis}

Adsorption isotherms of lysozyme on Tris-cryogel were investigated batchwise at pH 7.5. A mass of $0.020 \mathrm{~g}$ of dried cryogels was previously incubated with $0.5 \mathrm{~mL}$ of sodium phosphate buffer $(0.02 \mathrm{~mol} / \mathrm{L}, \mathrm{pH} 7.5)$ for $30 \mathrm{~min}$. Then, $1 \mathrm{~mL}$ of the same buffer containing lysozyme (concentration ranging from 0.5 to $40 \mathrm{mg} / \mathrm{mL}$ ) was added to the tubes and incubated overnight at constant temperature $\left(15^{\circ} \mathrm{C}\right.$ and $\left.35^{\circ} \mathrm{C}\right)$. The lysozyme concentration in the supernatant and initial concentration were determined via spectrophotometry according to the method of Bradford [21] at $595 \mathrm{~nm}$. The experiments were conducted in triplicate. The amount of adsorbed lysozyme was determined by mass balance (Eq. (7)).

$q=\frac{V\left(C_{O}-C\right)}{M}$

where $q(\mathrm{mg} / \mathrm{g})$ is the lysozyme concentration in the solid phase, $C$ $(\mathrm{mg} / \mathrm{mL})$ is the lysozyme concentration in the liquid phase after reaching equilibrium, $C_{o}(\mathrm{mg} / \mathrm{mL})$ is the initial concentration of lysozyme, $V(\mathrm{~mL})$ is the liquid phase volume and $M(\mathrm{mg})$ is the adsorbent weight.

The Langmuir isotherm (Eq. (8)), which has been widely used to describe the protein adsorption, was adjusted to the equilibrium data obtained in this work. Model parameters were estimated by a non-linear regression.

$q=\frac{q_{\max } \cdot C}{K_{d}+C}$

where $q_{\max }(\mathrm{mg} / \mathrm{g})$ is the adsorption capacity and $K_{\mathrm{d}}(\mathrm{mg} / \mathrm{mL})$ the dissociation constant.

The apparent change in the Gibbs free energy of adsorption $\left(\Delta G^{0}\right.$ ) for each temperature was determined from the thermodynamic equilibrium constant, $K_{d}$, according to Eq. (9):

$\Delta G^{0}=-R T \ln K_{d}$

where $T(\mathrm{~K})$ is the absolute temperature and $R(8.314 \mathrm{~J} /(\mathrm{mol} \mathrm{K}))$ is the universal gas constant. The value of $K_{d}$ is determined as:

$K_{d}=\left(\frac{d q}{d C}\right)_{C \rightarrow 0}$

Apparent enthalpy and entropy $\left(\Delta H^{0}\right.$ and $\left.\Delta S^{0}\right)$ changes were estimated according to the Van't Hoff relationship, given by:

$\ln K_{d}=-\frac{\Delta H^{0}}{R T}+\frac{\Delta S^{0}}{R}$

The mean values of $\Delta H^{0}$ and $\Delta S^{0}$ were estimated by linear regression using Eq. (11).

\subsubsection{One-step purification of lysozyme from chicken egg white}

Chicken egg white (EW) was prepared daily from fresh eggs and separated by filtration in a $1 \mathrm{~mm}$ aperture sieve. Egg whites were gently stirred and then centrifuged at $12,000 \mathrm{~g}$ for $15 \mathrm{~min}$. The supernatant was recovered and filtered on a $1.2 \mu \mathrm{m}$ cellulose acetate membrane.

2.2.4.1. Effect of $p H$. the capture of lysozyme by the Tris-cryogel was investigated as a function of $\mathrm{pH}$. An HR 10/15 glass column (Ge Healthcare, USA) containing the Tris-cryogel was equilibrated with 4 column volume (CV) of phosphate buffer solution $(0.02 \mathrm{~mol} / \mathrm{L})$. Egg whites were diluted with equal volume of phosphate buffer (0.02 mol/L) at different $\mathrm{pH}$ values (7.5, 8.5 and 9.5) and pumped through the column at a flow rate of $2.0 \mathrm{~mL} / \mathrm{min}$. The adsorption experiments were done with frontal analysis. After the breakthrough formation, the column was washed with the same buffer and the elution of the adsorbed protein was performed applying $4 \mathrm{CV}$ of sodium phosphate buffer $(0.02 \mathrm{~mol} / \mathrm{L})$ containing $1.0 \mathrm{~mol} / \mathrm{L}$ of sodium chloride. The adsorption and elution profiles were monitored at $280 \mathrm{~nm}$. Protein fractions were collected during the elution step and stored for subsequent analysis. The assays were developed in a chromatographic system Äkta Pure 25 M (GE Healthcare Bio-Sciences AB, Uppsala, Sweden) at room temperature.

2.2.4.2. Effect of flow rate and dilution factor. The experiments were also studied as a function of dilution rate (1:0,1:2 and 1:4) of egg white with phosphate buffer (final concentration of $0.02 \mathrm{~mol} / \mathrm{L}$ ) and mobile phase flow rate $(2.0,4.0$ and $8.0 \mathrm{~mL} / \mathrm{min})$, with $\mathrm{pH}$ adjusted according to the results of the previous section. The experiment was arranged in a completely randomized design, using the dilution rate at each flow rate as the source of variation, with two repetitions. Linear regression analysis was performed and model accuracy (Eq. (12)) was evaluated using analysis of variance (ANOVA) with Fisher's statistical test (F-test), lack of fit and coefficient of determination $\left(R^{2}\right)$. Student $t$-test was performed for each coefficient of the equation. All statistical analyses were performed using SAS v.9 software.

$Y=b_{0}+b_{1} X_{1}+b_{2} X_{2}+b_{3} X_{1} * X_{2}+b_{4} X_{1}^{2}+b_{5} X_{2}^{2}$

where $Y$ stands for purification fold or yield, $X_{1}$ is the dilution rate, $X_{2}$ is the flow rate and $b_{i}$ is the regression coefficient.

\subsubsection{Quantification of lysozyme and total protein}

Lysozyme content was determined by a Shimadzu liquid chromatography (Model LC-10AD, Tokyo, Japan) with a diode array detector (Shimadzu, Japan). A reverse phase column (C18 apHera $^{\mathrm{TM}}, 250 \mathrm{~mm} \times 4.6 \mathrm{~mm}$, Supelco Analytical) was used for chromatographic separation. The mobile phase consisted of acetonitrile and trifluoroacetic acid $(0.1 \% \mathrm{v} / \mathrm{v})$ at a flow rate of $0.5 \mathrm{~mL} / \mathrm{min}$ [22]. A sample volume of $50 \mu \mathrm{L}$, previously filtered through a $0.22 \mu \mathrm{m}$ nylon membrane (Millipore, Bedford, USA) was injected into the system and monitored by UV detection at $220 \mathrm{~nm}$. Lysozyme was identified according to a previously calibration curve using the lysozyme standard.

Whole protein in the collected fractions was determined by the Bradford method [21] using bovine serum albumin as standard.

The collected fractions were also used to determine purity with SDS-PAGE electrophoresis. Electrophoresis was performed for $2 \mathrm{~h}$ at $100 \mathrm{~V}$ using a vertical gel electrophoresis system (BioRad, CA, USA) and with a $15 \%$ polyacrylamide gel. Coomassie brilliant blue R250 (0.27\% (w/v) in acetic acid:water:methanol (1:2.4:4, v/v/v) was used as the staining solution and the gels were destained using acetic acid:methanol:water $(1: 4.3: 9, \mathrm{v} / \mathrm{v} / \mathrm{v})$ solution.

\subsubsection{Lysozyme activity}

The activity (U) of the purified lysozyme samples was evaluated by the Shugar method [23], using a commercial kit (LY0100, Sigma Aldrich). A suspension of $0.1 \% \mathrm{~m} / \mathrm{v}$ Micrococcus lysodeikticus was prepared using the kit solvent. Samples of solutions containing lysozyme ( $30 \mu \mathrm{L}$ ) were added to $800 \mu \mathrm{L}$ of the suspension. The analysis was performed at room temperature. Lysozyme activity was defined as the quantity that caused the absorbance of the suspension to decrease by $0.001 / \mathrm{min}$ at $450 \mathrm{~nm}$.

\section{Results and discussion}

\subsection{Characterization of cryogel matrices}

In this study, cryogels were synthesized by radical cryopolymerization of AAm as a functional monomer with MAAm in the presence of AGE. Tris were covalently attached to the epoxy group on the cryogels to obtain Tris-cryogel $(11.7 \mathrm{~cm}$ column length). Swelling capacity was determined as $19.6 \pm 0.9 \mathrm{~g} / \mathrm{g}$ and presented 


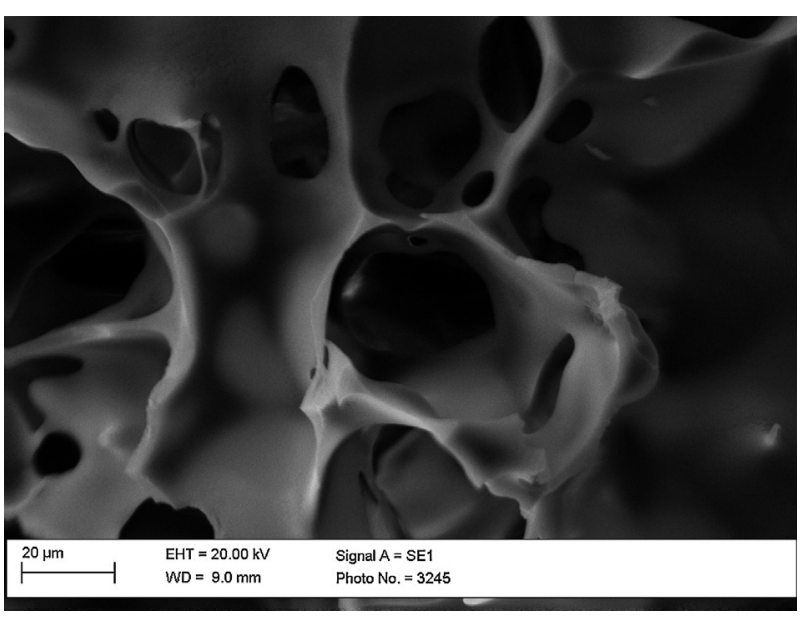

Fig. 1. Scanning electronic microscopy of Tris-cryogel.

as a sponge and elastic characteristic. A porous structure was observed by scanning electron microscopy (Fig. 1), with uniform and interconnected pores ranging from 10 to $80 \mu \mathrm{m}$ in size.

RTD curves were measured at different superficial velocities, $U$, from 0.6 to $10.2 \mathrm{~cm} / \mathrm{min}$. According to the momentum method, the mean residence time and variance were determined for each flow velocity. The bed porosity of 0.91 was determined by linear regression of Eq. (3) using the results for the mobile phase with $0 \%$ PEG. Axial dispersion coefficients varied from $2.0 \times 10^{-8} \mathrm{~m}^{2} / \mathrm{s}$ for lower mobile phase viscosity and flow velocity to $7.0 \times 10^{-6} \mathrm{~m}^{2} / \mathrm{s}$ for higher viscosity and flow velocity.

Fig. 2 presents $E_{\theta}$ curves at different flow velocities for mobile phases containing $0 \%(\mathrm{w} / \mathrm{w})$ PEG (A) and 7.5\% (w/w) PEG (B). The $E_{\theta}$ curves of Fig. $2 \mathrm{~A}$ are close to symmetrical, with dispersion number values $\left(\frac{D_{a x}}{u L}\right)$ around $10^{-2}$, indicating a small dispersion. On the other hand, when the PEG concentration was increased to $7.5 \%$ in the mobile phase, the $E_{\theta}$ curves appeared unsymmetrical (Fig. 2B). This is a result of a great deviation of the plug flow model, with a high degree of dispersion that could lead to lower adsorption column performance.

Fig. 3 presents the HETP as a function of fluid velocity for the different PEG concentrations in the mobile phase. The values of HETP when the PEG concentration was 0\% (the lowest PEG concentration) were the lowest. When the PEG concentration was increased in the mobile phase, HETP increased as well and was more dependent on mobile phase velocity, which concurs with $E_{\theta}$ curve analysis (Fig. 2). As a result, column adsorption capacity is reduced. Thus, we can expect higher purification process yield when using less concentrated feed solutions.

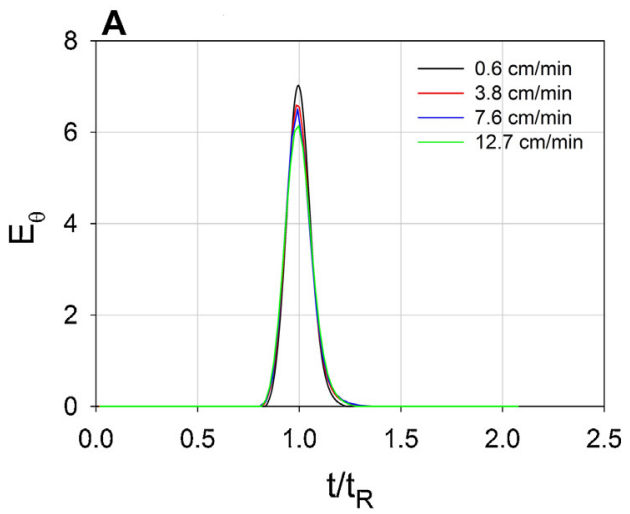

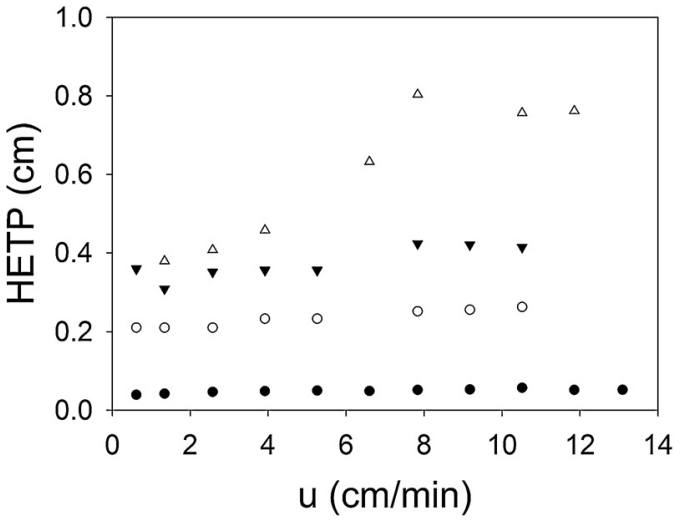

Fig. 3. HETP as a function of mobile phase superficial velocities and PEG concentrations of $0 \%(\bullet) ; 2.5 \%(\bigcirc) ; 5.0 \%(\nabla)$ and $7.5 \%(\Delta)$.

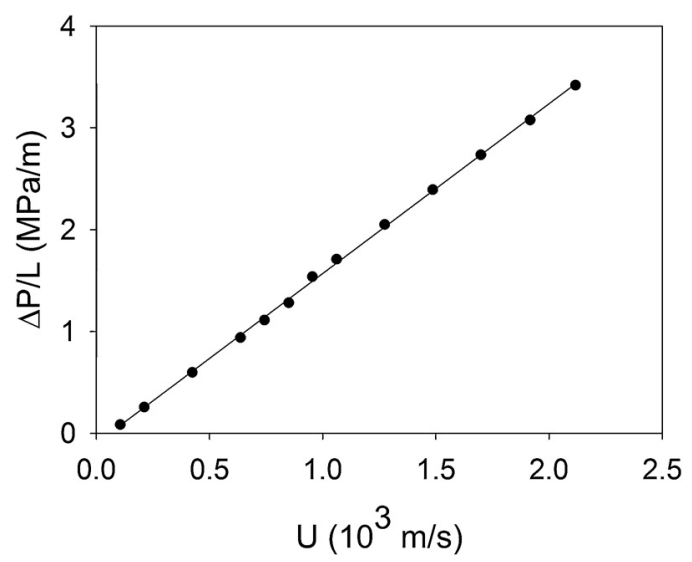

Fig. 4. Experimental data of $\Delta \mathrm{P} / \mathrm{L}$ at different liquid superficial velocities $(\bullet)$ and adjusted equation to determine permeability $(-) .\left(\mu_{\mathrm{w}}=1.003 \mathrm{~Pa} \cdot \mathrm{s}\right.$; $\left.K_{w}=5.9 \times 10^{-13} \mathrm{~m}^{2}\right)$

Experimental data for flow resistance is presented in Fig. 4. A linear relationship was observed between the pressure drop and flow rate. Hydraulic permeability $\left(K_{w}\right)$ was determined as $5.9 \times 10^{-13} \mathrm{~m}^{2}$ by the Darcy-Weisbach equation. This value was similar to those obtained for other supermacroporous monoliths $[15,24]$.

\subsection{Adsorption isotherms and thermodynamic analysis}

Fig. 5 shows the isotherms at temperatures of $15^{\circ} \mathrm{C}$ and $35^{\circ} \mathrm{C}$ for lysozyme in Tris-cryogel and Table 1 presents the adjusted param-

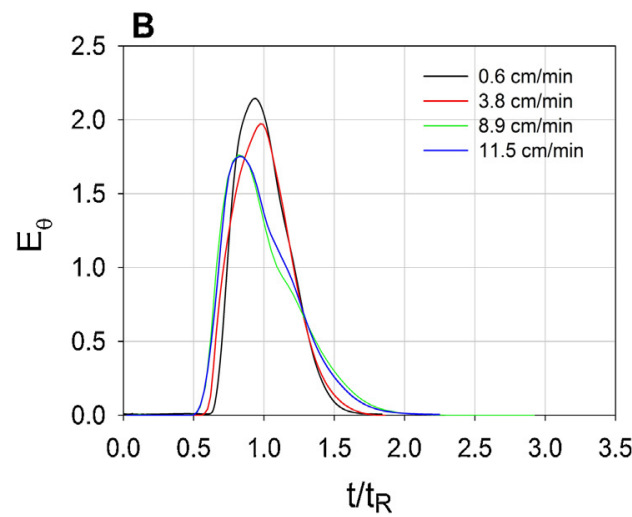

Fig. 2. Dimensionless $E_{\theta}$ curves at different flow velocities and two PEG concentrations in the mobile phase (A: $0 \% \mathrm{w} / \mathrm{w}$; $\left.\mathrm{B}: 7.5 \% \mathrm{w} / \mathrm{w}\right)$. 


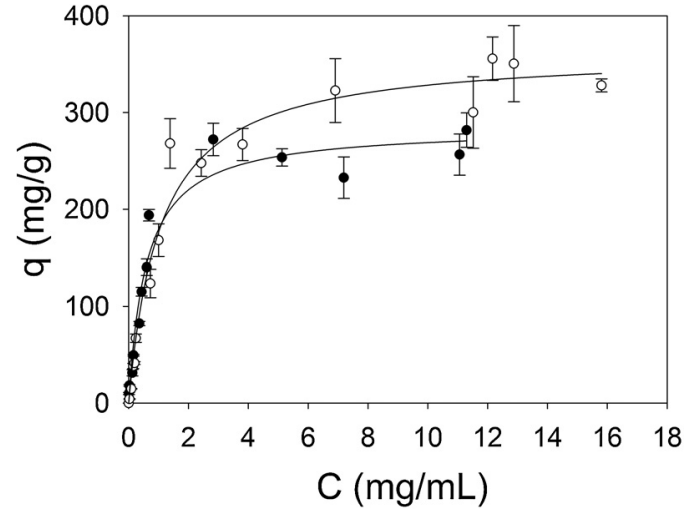

Fig. 5. Adsorption isotherms of lysozyme on Tris-cryogel. (•) $15^{\circ} \mathrm{C}$; (○) $35^{\circ} \mathrm{C}$.

Table 1

Adjusted isotherm parameters fitted by the Langmuir model.

\begin{tabular}{llllll}
\hline$T /\left({ }^{\circ} \mathrm{C}\right)$ & $q_{\max } /(\mathrm{mg} / \mathrm{g})$ & $P$ & $K_{1}$ & $P$ & $R^{2}$ \\
\hline 15 & 284.68 & $<0.0001$ & 0.59 & 0.0001 & 0.96 \\
35 & 363.10 & $<0.0001$ & 1.06 & $<0.0001$ & 0.98
\end{tabular}

eters of the Langmuir model. The Langmuir model fits very well to the experimental data throughout the concentration range. The saturation capacity of the adsorbent increased with increasing temperature. The maximum absorptive capacity obtained in this work was comparable or even higher than the values obtained in the literature [8,10,25,26]. Zhang et al. [9] used supports activated with Tris and obtained the maximum adsorptive capacity of $108.6 \mathrm{mg} / \mathrm{g}$.

To explain the forces involved in the adsorption process, a thermodynamic analysis was conducted and the thermodynamic properties are shown in Table 2. The Gibbs free energy values were negative, indicating that the adsorption process occurs spontaneously. Considering the greater absolute value of enthalpy, we

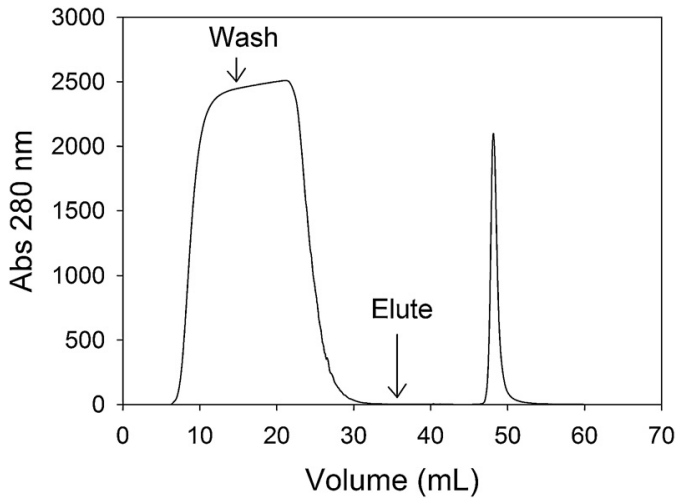

Fig. 6. Adsorption profile of the purification of lysozyme from EW, with the three main steps of feedstock loading, washing and elution.

can state that lysozyme adsorption in the adsorbent produced is governed by enthalpy.

\subsection{One step purification of lysozyme from chicken egg white}

Fig. 6 illustrates the single peak obtained after feedstock (EW) load, washing and elution, which corresponds to lysozyme adsorbed onto the cryogel matrix. Results demonstrate the specificity of the Tris-cryogel.

Table 2

Values of $\Delta G^{0}, \Delta H^{0}$ e $\Delta S^{0}$ calculated.

\begin{tabular}{lll}
\hline Parameters $(\mathrm{kJ} / \mathrm{mol})$ & $0 \mathrm{~mol} / \mathrm{L} \mathrm{NaCl}$ & \\
\cline { 2 - 3 } & $15^{\circ} \mathrm{C}$ & $35^{\circ} \mathrm{C}$ \\
\hline$\Delta \mathrm{G}^{0}$ & -14.80 & -14.95 \\
$\Delta \mathrm{H}^{0}$ & -12.63 & \\
$\mathrm{~T} \Delta \mathrm{S}^{0}$ & 2.24 &
\end{tabular}
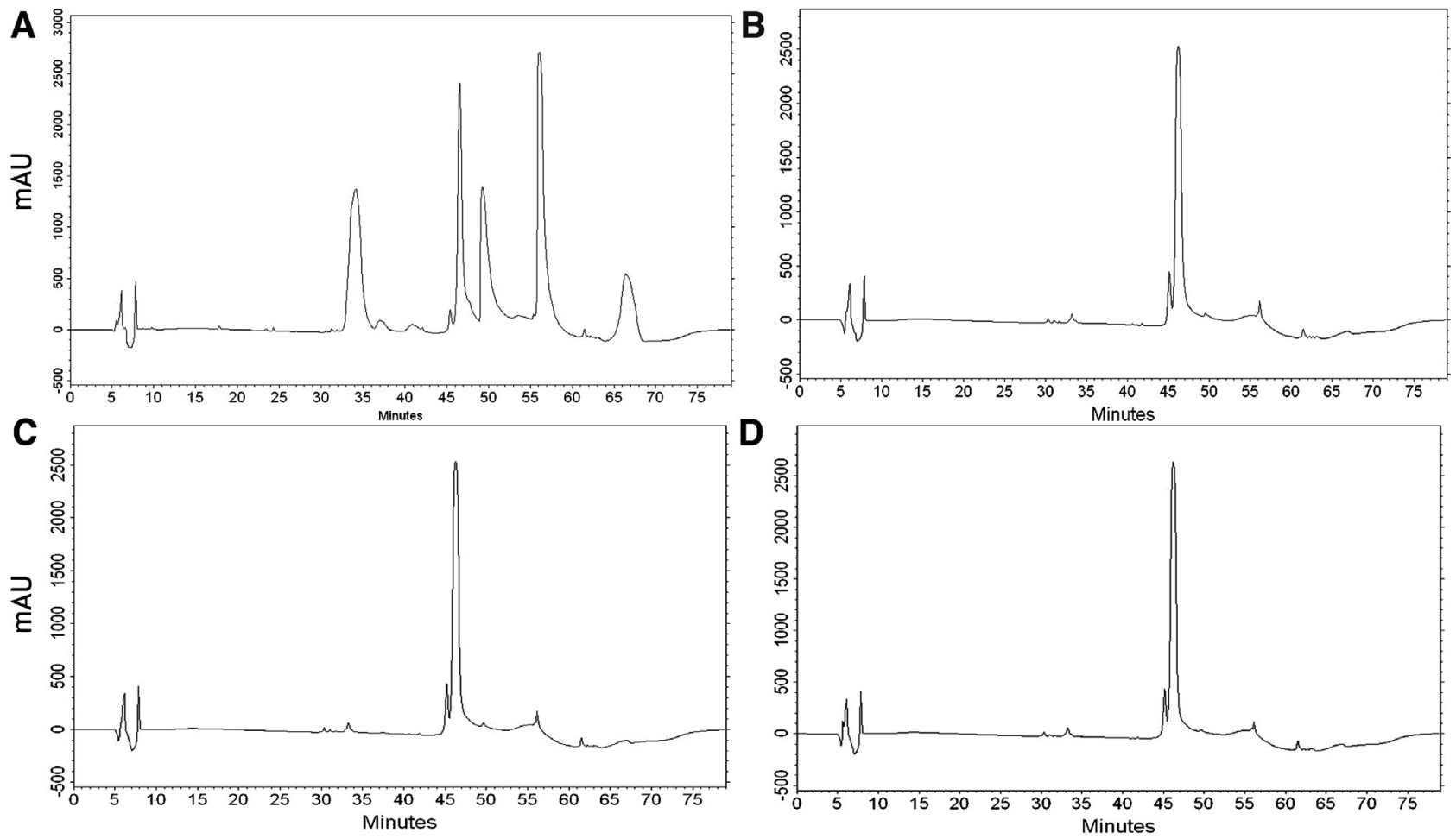

Fig. 7. Chromatographic profile of (A) feedstock solution and eluted fractions collected at different pH values: (B) 7.5 , (C) 8.5 and (D) 9.5 . 
Table 3

One step purification of lysozyme from egg white: effect of $\mathrm{pH}$.

\begin{tabular}{|c|c|c|c|c|c|c|}
\hline Sample & $\mathrm{pH}$ & Total Protein (mg) & Total Activity (U) & Specific Activity (U/mg) & Purification (-fold) & Yield (\%) \\
\hline EW & 7.5 & 323.20 & 445000 & 1377 & 1 & 100 \\
\hline Eluted & 7.5 & 2.15 & 136036 & 62207 & 45 & 31 \\
\hline EW & 8.5 & 298.0 & 548167 & 1839 & 1 & 100 \\
\hline Eluted & 8.5 & 2.1 & 113350 & 53611.0 & 29 & 21 \\
\hline EW & 9.5 & 266.0 & 624443 & 2438 & 1 & 100 \\
\hline Eluted & 9.5 & 1.59 & 78417 & 50285 & 21 & 13 \\
\hline
\end{tabular}

Table 4

One step purification of lysozyme from egg white: effect of dilution rate and flow rate.

\begin{tabular}{|c|c|c|c|c|c|c|c|}
\hline Sample & Flow rate $(\mathrm{mL} / \mathrm{min})$ & Dilution rate & Total Protein (mg) & Total Activity (U) & Specific Activity (U/mg) & Purification (-fold) & Yield (\%) \\
\hline EW & & $1: 0$ & 312.7 & 746,000 & 2386 & 1 & 100 \\
\hline Eluted & 2 & $1: 0$ & 1.4 & 91,052 & 66,544 & 28 & 12 \\
\hline Eluted & 4 & $1: 0$ & 1.4 & 92394 & 66,087 & 28 & 12 \\
\hline Eluted & 8 & $1: 0$ & 1.5 & 97,010 & 63,842 & 27 & 13 \\
\hline EW & & $1: 2$ & 100.3 & 354,667 & 3454 & 1 & 100 \\
\hline Eluted & 2 & $1: 2$ & 2.1 & 129140 & 60,302 & 17 & 36 \\
\hline Eluted & 4 & $1: 2$ & 2.0 & 133,966 & 66,253 & 19 & 38 \\
\hline Eluted & 8 & $1: 2$ & 1.4 & 140,340 & 75,197 & 24 & 40 \\
\hline EW & & $1: 4$ & 64.9 & 233,167 & 3591 & 1 & 100 \\
\hline Eluted & 2 & $1: 4$ & 2.0 & 165,600 & 83,669 & 23 & 71 \\
\hline Eluted & 4 & $1: 4$ & 2.2 & 169,145 & 78,695 & 22 & 73 \\
\hline Eluted & 8 & $1: 4$ & 2.1 & 167,218 & 80871 & 23 & 72 \\
\hline
\end{tabular}

\subsubsection{Effect of $p H$}

Fig. 7 shows the chromatograms of feed solution and eluted peaks for the different $\mathrm{pH}$ values studied. Feed solution presented an average lysozyme concentration of $1.87 \mathrm{mg} / \mathrm{mL}$ and average protein concentration of $11.4 \mathrm{mg} / \mathrm{mL}$. Independent of the $\mathrm{pH}$, the eluted samples essentially showed the peak corresponding to lysozyme, evidencing the specific interaction of this protein with the adsorbent, confirming the results obtained by Quan et al. [12].

Purification fold and yield parameters, after one step purification of lysozyme in the Tris-cryogel under different $\mathrm{pH}$ values, are shown in Table 3. Purification fold and yield were affected by the $\mathrm{pH}$, with the highest values occurring at $\mathrm{pH} 7.5$. This $\mathrm{pH}$ is farthest from the isoelectric point of lysozyme, so protein-protein interactions are reduced and the orientation of the adsorption site of the protein is more suitable for interaction with Tris. Lysozyme retained catalytic activity after the chromatographic step, validating the use of the present technique in the purification process. The purified enzyme showed a single band after SDS-PAGE under denaturing conditions (Fig. 8).

\subsubsection{Effect of flow and dilution rates}

The experimental results of purification fold and yield are presented in Table 4 and were subjected to ANOVA at 95\% of significance (Table 5). Only the dilution rate significantly affected the purification fold and yield ( $\mathrm{p}<0.05$ ).

As shown in Table 4, the adsorbed protein, and therefore the total activity in the eluted fraction, increased when EW was more diluted. According to Hatti-Kaul and Mattiasson [27], two factors govern chromatographic processes: solute distribution between stationary and mobile phases, which interferes with retention and solubility, and axial dispersion, which influences column efficiency. Considering that lysozyme is only $3.4 \%$ of the total protein and is a small protein compared to the other EW proteins, it is plausible that steric hindrance could occur because of the high protein concentration, hindering lysozyme access to the Tris-cryogel adsorption sites. Moreover, the HETP analysis showed that, the higher the PEG concentration and consequent higher mobile phase viscosity, the higher the HETP value (Fig. 3). This could also negatively affect the column yield since EW is a highly viscous solution.

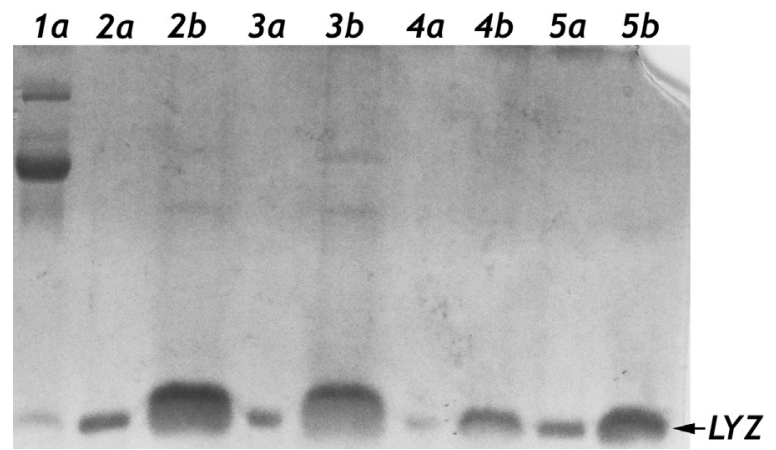

Fig. 8. SDS-PAGE 15\%: (1) Feed solution; (2) eluted samples obtained at pH 7.5 (3) 8.5 (3) and (4) 9.5; (5) lysosome standard ( $1 \mathrm{mg} / \mathrm{mL}$ ). (a) Ten $\mu$ L injection; (b) Fifteen $\mu \mathrm{L}$ injection.

\section{Conclusions}

In this work, a new affinity cryogel activated with Tris hydroxymethyl aminomethane was produced and used for one step purification of lysozyme directly from the chicken egg white. Tris-cryogel morphology presented a characteristic interconnected porous structure with high permeability and low backpressure. Axial dispersion was studied with varying viscosities and flow velocities in the mobile phase. At low viscosity, axial dispersion was very low, with the flow profile resembling a plug flow. HETP was the lowest and not dependent of flow velocity. Increasing viscosity however, a great deviation of the plug flow model with high degree of dispersion was observed. In this case, HETP increased and was dependent on fluid velocity.

Equilibrium adsorption of lysozyme in the Tris-cryogel presented a dependence of temperature, showing that higher temperatures favor the maximum adsorption capacity. Thermodynamic analysis indicated that adsorption processes were spontaneous since the Gibbs free energy values were negative and enthalpically driven. One step lysozyme purification from EW indicated that the highest yield and purification fold was achieved at pH 7.5 and the highest dilution rate. The hysteric hindrance phenomenon and high HETP may be responsible for the reduced yield and purification fold. Finally, the Tris-cryogel successfully purified 
Table 5

ANOVA performed on yield results.

\begin{tabular}{lllllll}
\hline Source & DF & \multicolumn{2}{l}{ Yield (\%) } & & \multicolumn{2}{l}{ Purification (-fold) } \\
\cline { 6 - 7 } \cline { 5 - 6 } & & SS & Fvalue & & SS & Fvalue \\
\hline$X_{1}$ & 1 & 85552.658 & $1115.30^{*}$ & & 1265.483 & $19.86^{*}$ \\
$X_{2}$ & 1 & 63.934 & 0.83 & & 98.890 & 1.55 \\
$X_{1}{ }^{*} X_{1}$ & 1 & 20369.451 & $265.55^{*}$ & & 317.401 & $4.98^{*}$ \\
$X_{2}{ }^{*} X_{2}$ & 1 & 0.9524 & 0.12 & & 0.9995 & 0.16 \\
$X_{1}{ }^{*} X_{2}$ & 1 & 0.2502 & 0.03 & & 79.263 & 1.24 \\
Model & 5 & 10599.80 & $276.37^{*}$ & & 1771.032 & $5.56^{*}$ \\
Error & 12 & 920.495 & & & 764.729 & \\
Lack of fit & 3 & 54.201 & 0.19 & & 367.057 & 2.77 \\
Pure error & 9 & 866.294 & & & 397.672 & \\
Total & 17 & 10691.86 & & & 2535.761 & \\
$R^{2}$ & & 0.99 & & & 0.70 & \\
\hline
\end{tabular}

DF: degrees of freedom, SS: sum of squares.

${ }^{*}(\mathrm{p}<0.05)$.

the lysozyme directly from CW in one step, with high yield (72\%) and purification fold of 23 . The Tris-cryogel produced can be used in high throughput purification of this protein.

\section{Acknowledgements}

The authors thank FAPEMIG, CAPES and CNPq for their financial support.

\section{References}

[1] M.G.B. Koblitz, Matérias primas alimentícias: composição e controle de qualidade, Guanabara Koogan, Rio de Janeiro, 2011.

[2] E.D.N.S. Abeyrathne, H.Y. Lee, D.U. Ahn, Egg white proteins and their potential use in food processing or as a nutraceutical and pharmaceutical agents - a review, Poult. Sci. 92 (2013) 3292-3299.

[3] E.C. Dragan, Advanced Separations by Specialized Sorbents, CRC Press, Boca Raton, 2014.

[4] L.R. Wetter, H.F. Deutsch, Immunological studies on egg white proteins. IV. Immunochemical and physical studies of lysozyme, J. Biol. Chem. 192 (1951) 237-242.

[5] R.E. Canfield, The amino acid sequence of egg white lysozyme, J. Biol. Chem. 238 (1961) 2698-2707.

[6] Y. Luding, S. Shaochuan, Y. Junxian, Y. Kejian, Isolation of lysozyme from chicken egg white using polyacrylamide-based cation-exchange cryogel, Chin. J. Eng. 19 (2011) 876-880.

[7] E.B. Altintas, N. Tüzmen, N. Candan, A. Denizli, Use of magnetic poly(glycidil methacrylate) monozise beads for the purification of lysozyme in batch systems, J. Chromatogr. B 853 (2007) 105-113.
[8] Z. Li, M. Cao, W. Zhang, L. Liu, J. Wang, W. Ge, Y. Yuang, T. Yue, R. Li, W. Yu, Affinity chromatography of lysozyme with Reactive Red 120 modified magnetic chitosan microspheres, Food Chem. 145 (2014) 749-755.

[9] G. Zhang, Q. Cao, N. Li, K. Li, F. Liu, Tris (hydroxymethil)aminomethane-modified magnetic microspheres for rapid affinity purification of lysozyme, Talanta 83 (2011) 1515-1520.

[10] F.J. Wolman, G.J. Coppelo, A.M. Mebert, A. Targovnik, M.V. Miranda, A.A.N. del Canizo, L.E. Diaz, O. Cascone, Egg white lysozyme purification with a chitin-silica-based affinity chromatographic matrix, Eur. Food Res. Technol. 231 (2010) 181-188.

[11] E.B. Altintas, A. Denizli, Monosize poly(glycidyl methacryate) beads for dye-affinity purification of lysozyme, Int. J. Biol. Macromol. 38 (2006) 99-106.

[12] L. Quan, D. Wei, X. Jiang, Y. Liu, Z. Li, N. Li, K. Li, F. Liu, L. Lai, Resurveying the Tris buffer solution: the specific interaction between tris (hydroxymethyl)aminomethane and lysozyme, Anal. Biochem. 378 (2008) 144-150.

[13] T. Kang, Y. Niu, G. Jin, Visualization of the interaction between tris and lysozyme with a biosensor based on total internal reflection imaging ellipsometry, Thin Solid Films 571 (2014) 463-467.

[14] X.-D. Tong, X.Y. Dong, Y. Sun, Lysozyme adsorption and purification by expanded bed chromatography with a small-sized dense adsorbent, Biochem. Eng. J. 12 (2002) 117-124.

[15] B.M.A. Carvalho, S.L. Da Silva, L.H. Da Silva, V.P.R. Minim, M.C.H. Da Silva, L.M. Carvalho, L.A. Minim, Cryogel poly(acrylamide): Synthesis: structure and applications, Sep. Purif. Rev. 43 (2014) 241-262.

[16] G. Ertürk, B. Mattiasson, Cryogels-versatile tools in bioseparation, J. Chromatogr. A 1357 (2014) 24-35.

[17] I. Savina, B. Mattiasson, I.Y. Galaev, Graft polymerization of acrylic acid onto macroporous polyacrylamide gel (cryogel) initiated by potassium diperiodatocuprate, Polymer 46 (2005) 9596-9603.

[18] T. Furusawa, M. Suzuki, J.M. Smith, Rate parameters in heterogeneous catalysis by pulse technique, Catal. Rev. 31 (1976) 43-76.

[19] O. Levenspiel, Chemical Reaction Engineering, third edition, John Wiley \& Sons. Inc., New York, 1999.

[20] G. Guiochon, The limits of the separation power of unidimensional column liquid chromatography, J. Chromatogr. A 1126 (2006) 6-49.

[21] M.M. Bradford, A rapid and sensitive method for the quantitation of microgram quantities of protein utilizing the principle of protein-dye binding, Anal. Biochem. 72 (1976) 248-254.

[22] Y.H. Liao, M.B. Brown, G.P. Martin, Turbidimetric and HPLC assays for the determination of formulated lysozyme activity, J. Pharm. Pharmacol. 53 (2001) 549-554.

[23] D. Shugar, The measurement of lysozyme activity and the ultra-violet inactivation of lysozyme, Biochim. Biophys. Acta 8 (1952) 302-541.

[24] K. Yao, S. Shen, J. Yun, L. Wang, X. He, X. Yu, Preparation of polyacrylamide-based supermacroporous monolithic cryogel beds under freezing-temperature variation conditions, Chem. Eng. Sci. 61 (2006) 6701-6708.

[25] S. Oncel, L. Uzun, B. Garipcan, A. Denizli, Synthesis of phenylalanine-containing hydrophobic beads for lysozyme adsorption, Ind. Eng. Chem. Res. 44 (2005) 7049-7056.

[26] J. Sun, Y. Su, S. Rao, Y. Yang, Separation of lysozyme using superparamagnetic carboxymethyl chitosan nanoparticles, J. Chromatogr. B 879 (2011) 2194-2200.

[27] R. Hatti-Kaul, B. Mattiasson, Isolation and Purification of Proteins, Marcel Dekker, New York, 2003 